\title{
ANÁLISE DE INDICADORES QUE CONTRIBUEM PARA EVASÃO ESCOLAR NOS CURSOS TÉCNICOS DE EDUCAÇÃO A DISTÂNCIA NA AMAZÔNIA: ESTUDO DE CASO NO IFPA CAMPUS TUCURUÍ
}

\author{
TUCURUÍ/PA JULHO/2018
}

\author{
Douglas Bechara Santos - UFPA - douglasbechara@gmail.com \\ Viviane Almeida dos Santos - UFPA - viviane.almeida@gmail.com \\ Heleno Fülber - UFPA - fulber@gmail.com \\ Tipo: Investigação Científica (IC) \\ Natureza: Descrição de Projeto em Andamento \\ Categoria: Pesquisa e Avaliação \\ Setor Educacional: EDUCAÇÃO MÉDIA E TECNOLÓGICA
}

\begin{abstract}
RESUMO
Parte da região amazônica possui ambiente particular com dificuldades de acesso, locais sem energia, com conexão a internet de baixa velocidade e até regiões com isolamento social. Nesse contexto, a educação na modalidade a distância torna-se desafiadora. Como objetivo conhecer os principais fatores que contribuem para a evasão nos Cursos Técnicos de Educação a Distância do Instituto Federal de Educação, Ciência e Tecnologia do Pará - IFPA/Campus Tucuruí, bem como compreender quais elementos podem contribuir para minimizar a evasão, realizou-se uma pesquisa qualitativa com abordagem exploratória e descritiva utilizando como metodologia o estudo de caso. Como técnica para a coleta de dados faz uso da pesquisa documental, envolvendo documentação indireta e um questionário. Como metodologia para análise dos dados utiliza a análise textual discursiva. Entre os principais resultados esperados, no que se refere aos fatores que contribuem para a evasão nos cursos técnicos estão: detectar quais os fatores que desencadeiam a evasão escolar. Como proposta, será desenvolvido um estudo de caso a qual é apresentado uma estrutura formativa para servir de apoio a tomada de decisão por parte da gestão dos cursos de educação a distância na instituição.
\end{abstract}

Palavras-chave: Gestão EAD, Evasão, Curso Técnico, Amazônia. 
INTRODUÇÃO

A educação a distância - EAD compreende-se desde carreiras universitárias até formação específica. Tem registro de início em 1881 na Universidade de Chicago que ofertava curso de hebraico por correspondência. No Brasil, os maiores responsáveis pela educação a distância, que teve registro na década de 1960, foram o Instituto Universal Brasileiro e Instituto Monitor, ao qual eram ofertados cursos via material impresso e rádio [RIBEIRO, 2018].

Hoje, no Brasil, de maneira explosiva, o crescimento e expansão por instituições que oferecem algum tipo de curso a distância ganhou as graças da sociedade. Esse crescimento tem alcançado índices significativos e vem ocorrendo devido a exigência do mercado quanto a profissionais qualificados e emergência na formação de professores do ensino fundamental e outros níveis [SEGENREICH, 2013].

Isso tudo é apenas o começo, o mercado de trabalho exige profissionais cada vez mais especializados e a EAD é uma modalidade de ensino inclusiva que permite avançar na democratização do acesso à educação qualificando profissionais para o mercado de trabalho.

Nesse contexto, a EAD torna-se uma grande fonte de renda para instituições privadas e a forma mais viável de atingir maior volume de pessoas para educação pública. Conforme Pereira [2009], constata-se a abertura da educação superior como um amplo e lucrativo campo de exploração para grandes grupos empresariais, corroborada com dados da UNESCO. Contudo, a expansão mercantilizada do ensino superior - já em curso e concentrada nos países periféricos e EUA - precisa ser sustentada por elementos ideológicos que justifiquem tal processo e anulem a concepção de direito à educação pública superior, agora transmutada em um "serviço". [PEREIRA, 2009].

É o início de um tendência muito maior, o crescimento da oferta de cursos na educação básica e na pós-graduação stricto sensu reforçam a vocação prática da $E A D$, com 1.233 ofertas de cursos livres corporativos na área de treinamento operacional [CENSO, 2016].

No entanto a principal barreira enfrentada pelas instituições ofertantes de curso EAD é a evasão escolar. Compreender quais elementos podem contribuir para minimizar a evasão é uma ação de grande magnitude, levando-se em consideração que é uma questão importante para os negócios da EAD como um todo.

TAMARIZ [2015] destaca que a cada ano, as matrículas vêm aumentando na modalidade EAD, o que propicia uma educação flexível, se for levando em consideração o tempo e espaço físico. Porém, uma reflexão sobre o alto índice de evasão de alunos matriculados em algum tipo de modalidade EAD é relevante.

Por exemplo, no Brasil as taxas de evasão foram reportadas principalmente na faixa de $11 \%$ a $25 \%$, e as instituições públicas são as que menos conhecem esses motivos, entre $41 \%$ e $46 \%$ [CENSO, 2016]. 
Idealmente se o cenário fosse com uma compreensão racional dos indicadores de evasão, as instituições ofertantes não estariam padecendo desse mal.

Mais na verdade o que acontece é que nem todas as instituições afirmaram conhecer dos motivos da evasão e necessitam compreender quais elementos podem contribuir para minimizar a evasão, em especial as instituições públicas.

Nesta circunstância, a expansão dos cursos a distância e das avaliações demonstrarem um elevado nível de evasão, não há uma quantidade significativa de teses e dissertações que busquem identificar, explicar ou mesmo apontar soluções para essa situação [LIMA, 2015].

A maioria conclui que não há um único fator responsável pela desistência de alunos na $E A D$, a conjugação de vários fatores, sendo que em cada pesquisa ou instituição um se sobressai.

Considerando o contexto atual, esse trabalho propõe realizar uma pesquisa qualitativa nos cursos EAD do Instituto Federal de Educação Ciência e Tecnologia do Pará IFPA/Campus Tucuruí, com abordagem exploratória e descritiva além de utilizar como metodologia o estudo de caso.

Como técnica para a coleta de dados faz uso da pesquisa documental, envolvendo documentação indireta e um questionário. Como metodologia para análise dos dados utiliza a análise textual discursiva.

Observa-se que a região amazônica, caracterizada pela magnitude de seus recursos naturais e demasiada biodiversidade, possui paticulariedades que desafiam os habitantes ainda pouco conhecida pelo restante do país [LUCENA, 2012]. Associado as dificuldades de acesso, as vezes realizado por via fluvial, tornam-se regiões geograficas isoladas, deixando claro as dificuldades econômicas e sociais que limitam a população quanto a educação.

Em reflexão ao cenário de estudo do trabalho, encontra-se restrições na dificuldade de acesso ao polo presencial, ausênica de energia e conexão a internet precária ou inexistente nas residências dos discentes, o que gera um isolamento social e tecnológico da população.

Esses fatores contribuem com a evasão escolar em instituições que promovem a educação na modalidade a distância, pois, mesmo sendo visto como uma boa oportunidade de acesso ao ensino para a população da região, as dificuldades citadas contribuem com o baixo avanço de cursos EAD na Amazônia em comparação com outras localidades do país. Observa-se que nos últimos seis anos o crescimento de instituições de ensino no Brasil, que ofertam cursos a distância apresentando maior concentração nas regiões Sudeste e Sul, com apenas $2 \%$ de representatividade na região amazônica [CENSO, 2016].

[MAURICIO, 2012] Apresenta um trabalho com objetivo conhecer os principais fatores que contribuem para a evasão no Curso de Pedagogia a Distância de uma universidade 
pública do Estado de Santa Catarina. [SILVA JÚNIOR, 2017] Expõe o resultado de pesquisa, tendo como locus da pesquisa o Instituto Federal de Educação, Ciência e Tecnologia de Rondônia, campus Porto Velho Zona Norte quanto à evasão escolar na educação profissional. [DE CARVALHO, 2018] Evidencia o processo de gestão da educação a distância considerando a evasão - motivos e situações - e qual o papel das IES na retenção destes alunos. Poucos trabalhos têm como foco a região amazônica, assim como existe a carência de pesquisas, o que demonstra uma lacuna para atuação e revela aspectos inovadores para região.

\section{METODOLOGIA}

A pesquisa é qualitativa, com abordagem exploratória e descritiva e utiliza como metodologia o estudo de caso. Como técnica para a coleta de dados faz uso da pesquisa documental, envolvendo documentação indireta e um questionário. Como metodologia para análise dos dados utiliza a análise textual discursiva, conforme Moraes (2003).

Procedimentos necessários para entendimento do curso, assim como a ambientação ao Ambiente Virtual de Aprendizagem - AVA da instituição, caracterização do curso por meio de desenho que compreende os espaços, assim como o projeto pedagógico do curso.

A pesquisa documental, construção do questionário e entrevistas possibilitaram a organização e preparo para coleta de dados. Os dados foram coletados por meio de questionário impresso e entregue em mãos aos 43 alunos evadidos.

Os dados dos alunos foram fornecidos pela instituição por meio de ofício, o que viabilizou a procura e, associado ao reduzido espaço geográfico, foi possível localizar os alunos entrevistados.

A definição das relações que categoriza a análise dos fatores que provocam a evasão, sendo analisado alunos que registraram ou não a justificativa da evasão.

\section{RESULTADOS E DISCUSSÕES}

O tópico contém informações contidas no questionário preenchido pelos alunos evadidos do curso técnico em informática, e apresenta a análise dos dados obtidos através da pesquisa em gráficos que contêm informações sobre matrícula, evasão, permanência e motivos da evasão. 
Cada aluno evadido foi convidado a preencher o questionário citado, com o intuito de traçar o perfil desses alunos, identificar o(os) motivo(s) que levaram o mesmo a desistir do curso. Posteriormente esses dados poderão ser utilizados para elaborar estratégias a fim de minimizar a evasão.

A primeira informação obtida com o questionário diz respeito à faixa etária dos alunos. Sendo apresentada no gráfico 01 .

\section{Gráfico 02: Faixa etéria dos evadidos}

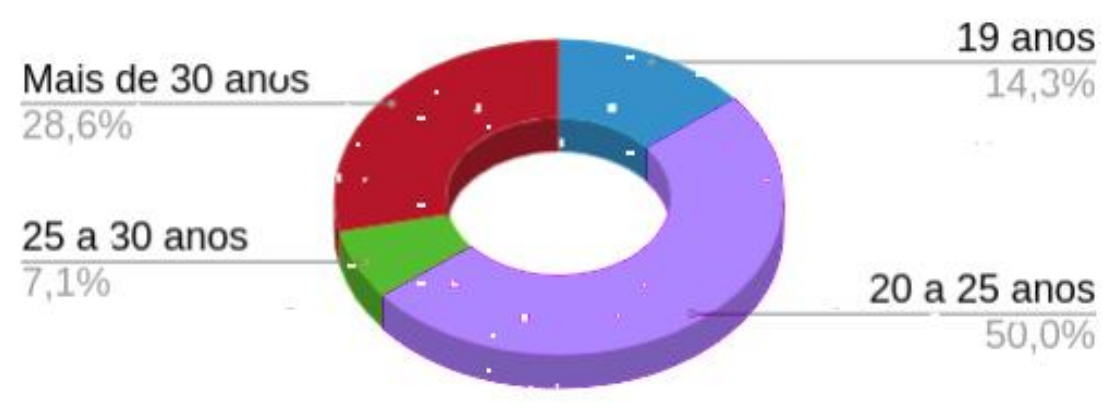

Fonte: Elaborado pelo autor.

O mesmo gráfico aponta que o maior percentual de alunos evadidos é na faixa etária de 20 a 25 anos. Seguida por alunos de mais de 30 anos, 19 anos e 25 a 30 anos. $O$ que não apresenta uma linearidade de evasão por faixa etária.

Moore e Kearley (2011) afirmam que "Embora seja verdade que os cursos de educação a distância às vezes são oferecidos a crianças em idade escolar para suplementar ou enriquecer o currículo em sala de aula, a maioria esmagadora dos alunos de educação a distância nos Estados Unidos é composta por adultos".

Em outra situação, alguns adultos se matriculam nos cursos de educação à distância para compensar uma educação de nível médio negligenciada.

A segunda informação obtida com o questionário, diz respeito ao sexo dos evadidos. Os resultados encontrados referentes à este tema estão apresentados na Tabela $01 \mathrm{e}$ Gráfico 02.

Tabela 01: Sexo dos evadidos

\begin{tabular}{|l|l|l|}
\hline Sexo & $\%$ & Ocorrências \\
\hline
\end{tabular}




\begin{tabular}{|c|c|c|}
\hline Masculino & $42,86 \%$ & 6 \\
\hline Feminino & $57,14 \%$ & 8 \\
\hline Total & $100 \%$ & 14 \\
\hline
\end{tabular}

Fonte: Elaborado pelo autor.

Os resultados apontam que a maior ocorrência de evasão se dá em alunos do sexo feminino, com $57,1 \%$ de representatividade, o que corresponde a 8 alunos no total de entrevistados.

O próximo resultado analisado do questionário, diz respeito à renda per capita dos alunos evadidos. O Gráfico 02 apresenta estes resultados.

Gráfico 02: Renda per capita dos evadidos

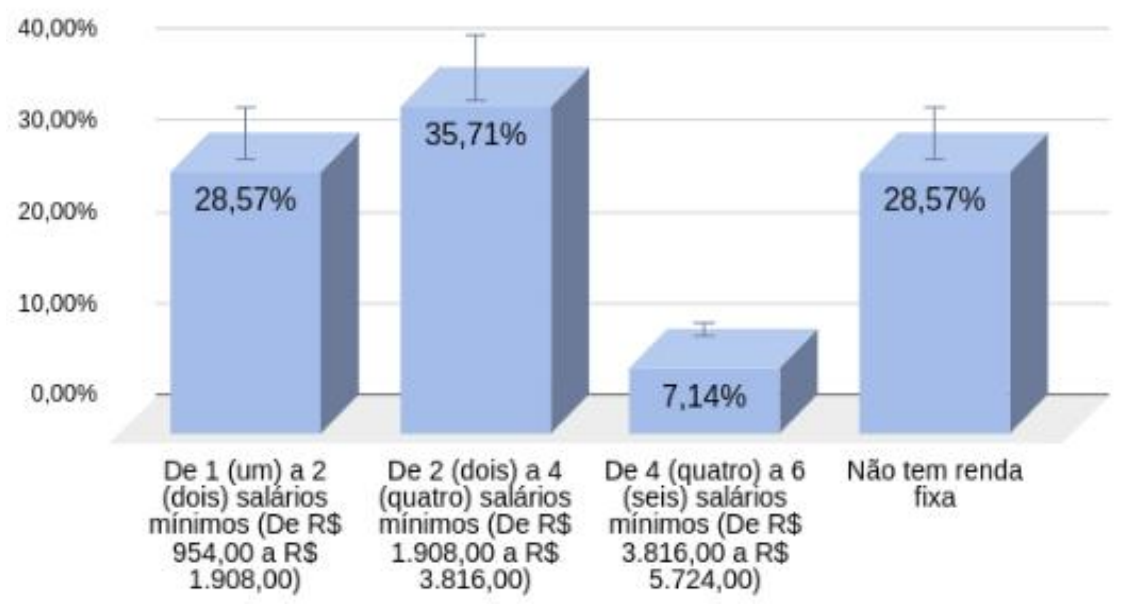

Fonte: Elaborado pelo autor.

Os resultados apontam que que o maior índice de evasão está nos alunos com renda per capita de dois a quatro salários mínimos, correspondendo a $35,71 \%$ dos entrevistados. Seguido por alunos que possuem renda per capita de um a dois salários mínimos e os que não possuem renda, com $28,57 \%$ de representatividade cada, ficando em menor número, os alunos evadidos com renda per capita de quatro a seis salários mínimos, aparecendo com 7,14\% dos entrevistados, totalizando 100\% dos alunos evadidos.

Estes resultados revelam que a baixa renda não é diretamente proporcional ao número de evadidos. Não sendo este, por sua vez o principal fator da evasão para esta amostragem. 
O último ponto do questionário que foi avaliado corresponde aos motivos de desistência do aluno. Este ponto pede aos alunos para apontar entre diversos motivos, os principais destes que os levaram a evasão e podem ser observados através dos Gráficos 03 e 04.

Gráfico 04: Motivos da desistência ou abandono

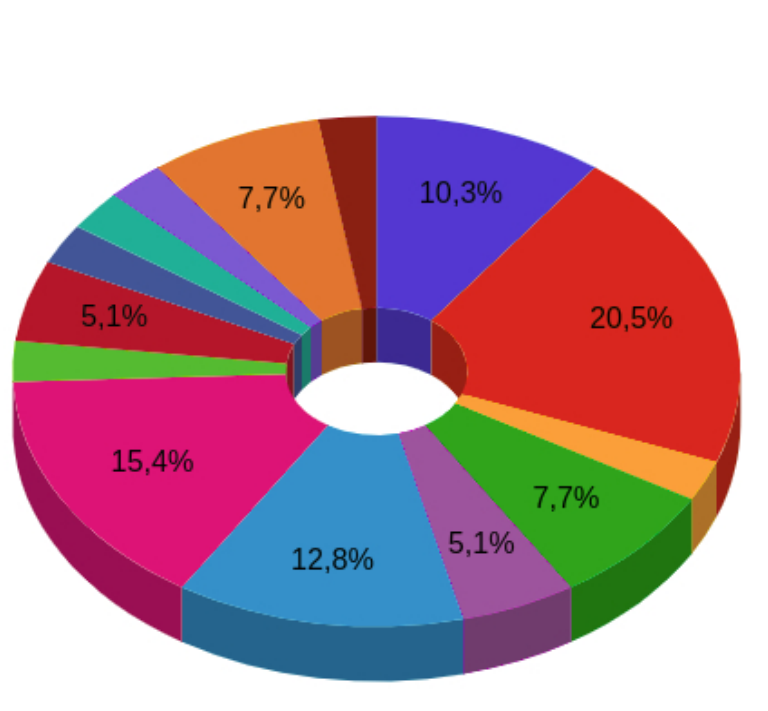
- Atraso no inicio do curso
- Relaçāo trabalho e estudo
- Localizaçāo do polo
- Doença
- Cursando outro curso
- Ausência de tempo
- Não adaptaçāo à EAD
- Aulas nāo ocorre conforme cronograma
- Nāo justificou - Nāo possuo infraestrutura para
um curso EAD
- Matricula em outro curso técnico
- Particulares
- Problemas no curso de EaD
- Transferência para outra cidade

Fonte: Elaborado pelo autor.

O Gráfico 4 contém a representatividade em percentual, de todas as respostas dadas pelos alunos, de acordo com as alternativas oferecidas. Cada cor corresponde a uma legenda descrita ao lado direito do gráfico.

As causas da evasão, registradas pelos alunos, são diversas. Dentre todas as opções contidas no questionário, destaca-se em maior ocorrência como motivo de desistência a relação trabalho estudo como principal fator para desistência, apresentada no Gráfico 4.

Gráfico 05: Motivos da desistência ou abandono

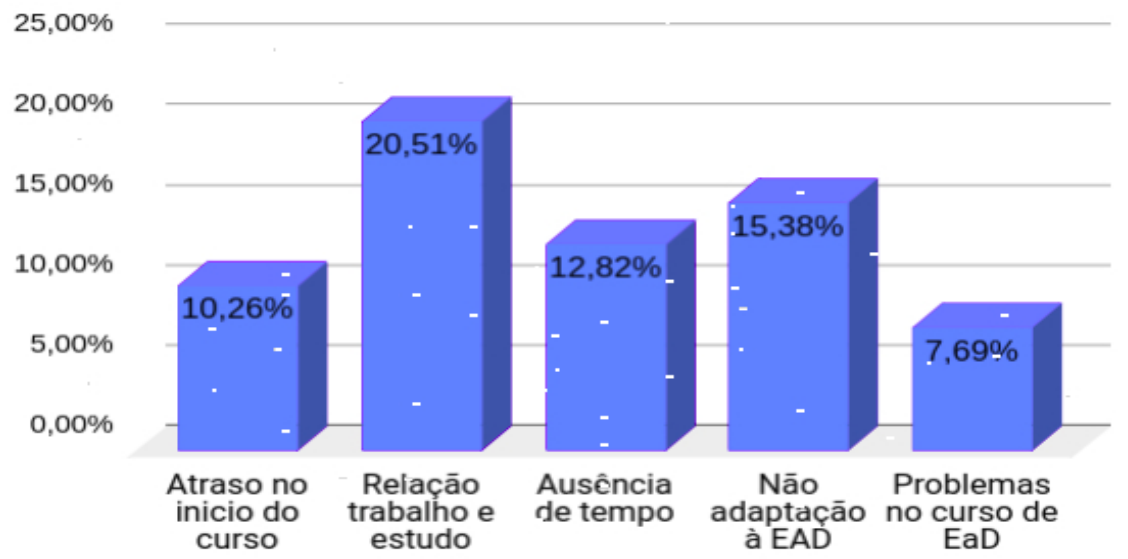


Fonte: Elaborado pelo autor.

Em maior percentual de motivo de desistência temos a relação trabalho e estudo, que corresponde a uma parcela de $20,51 \%$ dos alunos entrevistados. Seguida da não adaptação à $E A D$, com $15,38 \%$ de representatividade. A ausência de tempo, atraso no início do curso e problemas no curso de EAD também aparecem como motivadores à desistência, com 12,82\%, 10,26\% e 7,69\% respectivamente.

\section{CONSIDERAÇÕES FINAIS}

O levantamento dos resultados obtidos, nos permite traçar o perfil dos alunos evadidos do curso Técnico em Informática do IFPA campus Tucuruí.

Os resultados apontam que a maioria dos alunos evadidos é do sexo feminino, possui idade entre 20 a 25 anos, trabalha e detém dificuldade em conciliar trabalho e estudo.

Durante a pesquisa os entrevistados salientam que os encontros presenciais estipulados pela instituição dificultou a permanência no curso, tendo como premissa o cumprimento da jornada de trabalho de 8 horas associada a não liberação para participar dos encontros.

A não adaptação ao curso EAD, foi o segundo motivo mais apontado como causa da evasão do curso, sendo relatada dificuldade em relação a disciplina de estudo de forma autônoma, pois nenhum deles havia cursado outro curso EAD, e presumiam que a modalidade necessitava de menos dedicação que a modalidade presencial.

No que diz respeito à ausência de tempo relatada como terceiro fator de maior contribuição à evasão, foi justificada com fato dos alunos trabalharem e/ou possuírem outros afazeres, o que lhes suprimiu o tempo em realização as atividades e estudos.

O atraso para o início do curso relatado por aproximadamente $11 \%$ dos alunos, como motivo para a desistência, foi um ponto desmotivador, pois a espera para o início do curso tirou o foco desses alunos.

Os problemas no curso de EAD apontados como último fator motivador da evasão, foram citados pelos entrevistados, no que diz respeito à dificuldade de adaptação com fatores de ausência de professor mediador em sala de aula, pouca interação entre os alunos do curso e a falta de adaptação em realizar as atividades na plataforma virtual. 
A caracterização do perfil dos alunos evadidos entrevistados, revelou que a evasão se deu majoritariamente por dificuldade de conciliação entre trabalho e estudo, e consequente falta de tempo para se dedicar aos estudos.

Essa informação é válida para a instituição repensar a forma de planejar e reavaliar o curso, seja de modo em que os encontros presenciais realizados em intervalos maiores ou até mesmo que a disponibilidade do professor mediador presencial para atendimento dos alunos seja estendida para além do horário das aulas.

Por meio de investigação, conclui-se que a estrutura formativa proposta pela instituição abre precedentes à evasão escolar, fato esse apontado pelos dados em forma de gráficos.

Dessa forma, é proposto mudanças na estrutura formativa com fins a reduzir a evasão e possibilitar uma melhor relação ensino aprendizagem. A alteração do cronograma de encontros presenciais semanais com a oferta quinzenal, associado a horários flexíveis e com uma abordagem metodológica que tenha compatibilidade com o perfil formativo, dá a possibilidade de permanência da parcela de $20,51 \%$ dos desistentes.

A não adaptação a forma de oferta $E A D$, com $15,38 \%$ de representatividade, pode ser sanada com inserção de componente curricular de ambientação a EAD, associado a atividades complementares e treinamento ou orientação quanto ao entendimento da modalidade de ensino EAD e gestão do tempo.

A ampla divulgação antecipada do planejamento e cronogramas, assim como cumprir de forma rigorosa o protocolo planejado e maior integração da equipe formadora da a possibilidade de reduzir o obstáculo relatado pelos discentes, como atraso no início do curso e problemas no curso de EAD, com 10,26\% e 7,69\% respectivamente.

O esquadrinhamento científico com objetivo de conhecer os principais fatores que contribuem para a evasão escolar em uma instituição pública no contexto amazônico é um processo inovador e oferta a viabilidade dos discentes de dar continuidade ao processo ensino aprendizagem sobretudo com a adoção da proposta de mudança na estrutura formativa, apresentada no trabalho, por parte da instituição.

\section{REFERÊNCIAS}

Censo EAD.BR: Relatório analítico da aprendizagem a distância no Brasil 2016. São Paulo: Pearson Education do Brasil, 2017. Disponível em: . Acesso em 10 abril 2018. DE CARVALHO, GUILHERME JULIANI. Gestão de evasão em cursos de graduação em 
educação a distânica. Revista Doctrina E@ D, v. 1, n. 1, p. 54-75, 2018.

LIMA, Edileide Santos; JUNIOR, João Batista Bottentuit. Revisão Sistemática da Literatura: as causas da evasão nos cursos de Graduação a Distância/Systematic Literature Review: the evasion causes in undergraduate distance courses. Revista EducaOnline, v. 9, n. 3, p. 32-69, 2015.

LUCENA, Ketlen K. Teles et al. O desafio da educação a distância na Amazônia: Um estudo de caso. SIED: EnPED-Simpósio Internacional de Educação a Distância e Encontro de Pesquisadores em Educação a Distância 2012, 2012.

MAURíCIO, Wanderléa Pereira Damásio. De uma educação a distância para uma educação sem distância: a problemática da evasão nos Cursos de Pedagogia a distância. 2015.

MOORE, Michael; KEARSLEY, Greg G. Educação a distância: uma visão integrada. Tradução de Roberto Galman. São Paulo: Cengage Learning, 2011.

PEREIRA, Larissa Dahmer. Mercantilização do ensino superior, educação à distância e Serviço Social. Revista Katálysis, vol. 12, núm. 2, julio-diciembre, 2009, pp. 268-277. Universidade Federal de Santa Catarina, Brasil. Disponível: Acesso em: 10 abril. 2018. RIBEIRO, Silvio Paula; DA COSTA FREITAG, Viviane; SELLITTO, Miguel Afonso. Instrumento de mensuração de qualidade de materiais didáticos para a educação à distância. RIED. Revista Iberoamericana de Educación a Distancia, v. 21, n. 1, p. 239-259, 2018.

SEGENREICH, Stella Cecília Duarte; BUSTAMANTE, Silvia Branco Vidal. Políticas e práticas da Educação a Distância (EaD) no Brasil: entrelaçando pesquisas. Letra Capital Editora LTDA, 2013.

SILVA JÚNIOR, Adonias Soares da; FRANCISCO JUNIOR, Wilmo Ernesto. A evasão escolar no curso técnico em finanças oferecido pelo IFRO na EAD. 2017.

TAMARIZ, Annabell Del Real; DE SOUZA, Marcos. Educação a Distância no Brasil: perspectivas para redução na evasão de alunos matriculados. Revista Científica Linkania Master, v. 5, n. 1, 2015. 